\title{
Growth and Migration of Plasmodia of the Myxomycete Physarum polycephalum: the Effect of Carbohydrates, including Agar
}

\author{
By DAVID J. C. KNOWLES* AND MICHAEL J. CARLILE \\ Department of Biochemistry, Imperial College of Science and Technology, \\ London SW7 $2 A Z$
}

(Received 15 March 1978)

\begin{abstract}
A method for studying the growth and migration of myxomycete plasmodia on the surface of agar and other gels was devised. The migration rate of plasmodia of Physarum polycephalum was greatly reduced when nutrients that permit rapid growth were present, and slightly reduced by most sugars tested at $56 \mathrm{~mm}$, including some that were not utilized. The carbohydrate requirement of the myxomycete could be satisfied by a range of sugars and derivatives, including mannitol and agar, utilization of the latter being slight but definite. Fructose could be utilized as long as it was not the sole carbohydrate present.
\end{abstract}

\section{INTRODUCTION}

Carlile (1970) showed that plasmodia of the myxomycete Physarum polycephalum Schweinitz are capable of oriented migration (positive chemotaxis) towards nutrients. In order to understand the mechanism of chemotaxis it is necessary to determine the effect, if any, of attractants and related compounds on migration rate. The migration of plasmodia has been studied by Miller and co-workers (Miller \& Anderson, 1966, 1971; Rose et al., 1971; Denbo \& Miller, 1976) but their procedure, which involved feeding plasmodia on oat flakes and then permitting them to migrate on water agar, is unsuitable for discriminating between the direct effect of a substance on migration and any indirect effect through influencing growth, since the nutritional status of the plasmodia is uncertain. We have therefore developed methods for studying the migration of plasmodia in sterile conditions on gelled media with or without nutrients. These methods also permit the study of growth in surface culture, which approaches natural conditions more closely than the conventional shaken liquid culture, and have proved an effective way of examining the carbohydrate nutrition of plasmodia.

\section{METHODS}

Strain, media and routine culture. Strain i $\times$ A7029 (Carlile, 1972) was maintained in shaken liquid culture employing the semi-defined medium and methods described previously (Carlile, 1971). The basal salts and chelating agents/vitamins/peptone medium (SVP medium) contained ( \%, w/v): citric acid. $\mathrm{H}_{2} \mathrm{O}, \mathbf{0} \cdot 354$; $\mathrm{KH}_{2} \mathrm{PO}_{4}, 0 \cdot 2 ; \mathrm{CaCl}_{2} .2 \mathrm{H}_{2} \mathrm{O}, 0 \cdot 06 ; \mathrm{MgSO}_{4} .7 \mathrm{H}_{2} \mathrm{O}, 0 \cdot 06 ; \mathrm{Na}_{2} \mathrm{EDTA}, 0.022 ; \mathrm{FeCl}_{2} .4 \mathrm{H}_{2} \mathrm{O}, 0.006 ; \mathrm{ZnSO}_{4} .7 \mathrm{H}_{2} \mathrm{O}$, 0.003; thiamin hydrochloride, 0.004; biotin, 0.0005; haem, 0.005; peptone (Oxoid bacteriological), 1.0. $\mathrm{D}-$ Glucose (usually at $1 \%, \mathrm{w} / \mathrm{v}$ ) or other carbohydrates were added to this medium as indicated in the text. Except for routine culture or inoculum preparation, the carbohydrates used were filter-sterilized and added aseptically to the other components. Surface culture experiments were on media gelled with $2 \%(\mathrm{w} / \mathrm{v})$ Difco Bacto Agar or with $2.25 \%(\mathrm{w} / \mathrm{v})$ silica. The latter was prepared by the ion-exchange method of Smith (1951) from sodium silicate solution $\left(18 \% \mathrm{Na}_{2} \mathrm{O}\right.$ plus $36 \% \mathrm{SiO}_{2}$, Hopkins \& Williams) with Amberlite

* Present address: Department of Experimental Chemotherapy, May \& Baker Research Institute, Dagenham, Essex. 


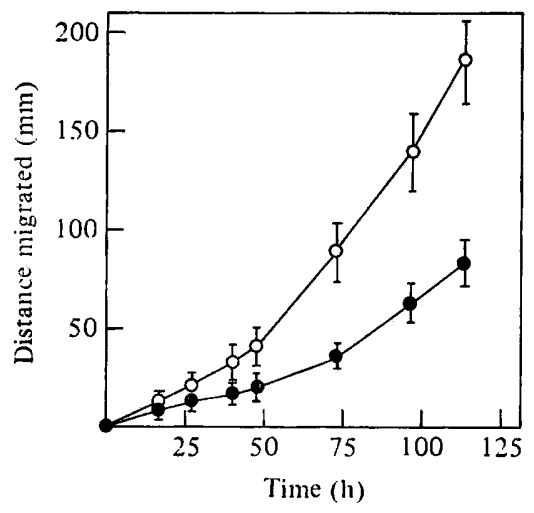

Fig. 1. Migration of plasmodia on SVP agar $(O)$ and SVP $1 \%$ glucose agar $(\odot)$. Vertical bars represent the standard errors.

IR-120 resin (BDH). All experiments were carried out at $24^{\circ} \mathrm{C}$ in the dark and aseptic methods were used throughout.

Migration experiments. Polypropylene trays, each with 20 grooves $(10 \mathrm{~mm}$ deep $\times 16 \mathrm{~mm}$ wide $\times 400 \mathrm{~mm}$ long), were sterilized by steam in the presence of glutaraldehyde vapour (Dodd et al.., 1974) and their plateglass tops were flame-sterilized with ethanol in a laminar flow cabinet. The grooves in the trays were filled with molten medium to a depth of $5 \mathrm{~mm}$ to provide tracks for migration which, when the medium had gelled, were inoculated at one end. Well nourished inocula were obtained from the margin of large plasmodia ( 3 to $5 \mathrm{~d}$-old and 100 to $200 \mathrm{~mm}$ diam.) growing on $5 \mathrm{~mm}$ deep SVP $1 \%$ starch agar in $250 \times 250 \mathrm{~mm}$ bioassay dishes; plugs of agar bearing plasmodium were cut with a $15 \mathrm{~mm}$ diam. corkborer. The large plasmodia were obtained by inoculation with plugs cut from a Petri dish culture, itself inoculated with microplasmodia pipetted from liquid culture. When inocula on SVP agar were required, plugs from the large plasmodia were placed at the ends of SVP agar tracks, allowed to migrate for 150 to $200 \mathrm{~mm}$, and then $15 \mathrm{~mm}$ diam. plugs were cut from the advancing margins of the plasmodia. Starved plasmodia were produced by centrifuging $(220 \mathrm{~g}, 1 \mathrm{~min})$ a liquid culture at maximum growth and pipetting the pellet evenly on to 20 pieces of Whatman no. 1 filter paper, which were then placed at the end of water agar tracks. The microplasmodia on each track fused overnight to give single plasmodia; $15 \mathrm{~h}$ after inoculation these were migrating at about $10 \mathrm{~mm} \mathrm{~h}^{-1}$. Migration was recorded by tracing the outlines of the plasmodial fronts on to the glass tray tops in black ink and photographing to provide a permanent record. Preliminary experiments had indicated that the intermittent dim light necessary for recording did not detectably influence migration. The distance migrated was taken as that from the front edge of the inoculum site to the most advanced point on the migrating plasmodium.

To estimate growth, plasmodia were floated off the tracks with distilled water or, when media containing salts were used, with $50 \mathrm{~mm}$-phosphate buffer. Plasmodia were then dried at $110^{\circ} \mathrm{C}$ for $15 \mathrm{~h}$ and weighed. Except where otherwise indicated, statistical procedures were from Snedecor \& Cochran (1974), the results of different treatments on growth and migration being compared by means of Student's $t$-test.

\section{RESULTS}

\section{Migration and growth on nutrient media gelled with agar}

Twenty tracks of SVP agar and 20 of SVP $1 \%$ glucose agar were inoculated with plasmodia on SVP $1 \%$ starch agar plugs. Migration rates on both media gradually increased, but did so less rapidly in the presence of glucose than in its absence (Fig. 1). A similar experiment in which plasmodia were harvested at intervals showed increases in dry weight; these were larger in the presence of glucose than in its absence. It was concluded that there is probably a roughly exponential increase in both dry weight and migration rate with time. The relationship between the dry weights of the individual plasmodia and the distance that they had migrated was linear (Fig. 2), implying that there was a uniform increment in growth per unit of distance migrated. This linear relationship was to be expected, since the advance of a plasmodium over a unit distance brings it into contact with a corresponding 


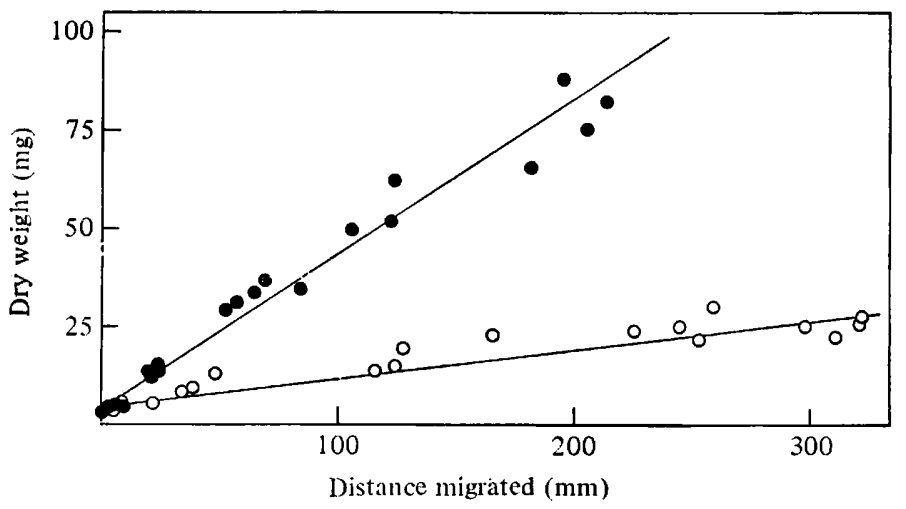

Fig. 2. Growth of plasmodia on SVP agar $(O)$ and SVP $1 \%$ glucose agar $(O)$ in relation to distance migrated. The straight lines were fitted by regression analysis; the correlation coefficient $r$ is 0.95 for SVP and 0.99 for SVP $1 \%$ glucose, with respective growth values of $73 \mu \mathrm{g} \mathrm{mm}^{-1}$ and $383 \mu \mathrm{g} \mathrm{mm}^{-1}$.

volume of medium. Hence the dry weight of plasmodium per mm migrated will be used as a measure of growth $\left(\mu \mathrm{g} \mathrm{mm}^{-1}\right)$.

\section{Agar and agarose as carbohydrate sources for P. polycephalum}

In SVP liquid medium $P$. polycephalum requires a carbohydrate to support growth (Carlile, 1970), whereas the above experiment established that growth occurs on SVP agar without added carbohydrate. Hence either carbohydrates are not required in surface culture, or agar, used as a gelling agent, is providing adequate carbohydrate to support growth. Experiments were therefore carried out with SVP and SVP 1\% glucose media gelled with agar and with silica. With SVP $1 \%$ glucose, the migration rates and growth on media gelled with agar and with silica were similar, hence silica gels do not interfere with migration or growth of well nourished plasmodia. On SVP media, however, growth and migration occurred with agar as a gelling agent, but with silica there was no growth and plasmodia turned into sclerotia after limited and irregular migration. Hence agar was acting as a carbohydrate source.

Agar has two main components, agarose and agaropectin (Araki, 1966). Since agarose is the simpler component, and is commercially available, experiments were carried out to determine the effectiveness of agarose compared with agar in supporting growth. Agarose constitutes about one-half of the dry weight of agar and is largely responsible for gelling; $1 \%$ agarose was therefore compared with $2 \%$ agar so that agarose content and gel strength were similar. Double strength media and gelling agents were autoclaved separately to minimize the possibility of acid hydrolysis of the gelling agent, and the agarose was of high purity (Grade 1, International Enzymes Ltd, Windsor, Berks). The growth on agar tracks was $75 \mu \mathrm{g} \mathrm{mm}^{-1}$ and on agarose $71 \mu \mathrm{g} \mathrm{mm}^{-1}$, with similar migration rates. Hence the ability of agar to support growth is due to partial utilization of the agarose component and not to contaminating carbohydrates.

To establish what concentration of glucose is equivalent to $2 \%$ agar in its effect, SVP media with various concentrations of glucose were prepared and gelled with silica. With glucose absent or at $0.01,0.02$ or $0.04 \%$, migration did not occur or was limited or irregular. With $0.05 \%$ glucose, the migration rate was similar to that on SVP agar without added glucose, as was growth: SVP plus $0.05 \%$ glucose silica, $79 \mu \mathrm{g} \mathrm{mm}^{-1}$; SVP agar, $72 \mu \mathrm{g} \mathrm{mm}^{-1}$. At higher glucose concentrations growth was greater and migration rates were lower. Hence $0.05 \%$ glucose supports growth and migration rates similar to those obtained with $2 \%$ agar in the absence of added carbohydrate. 


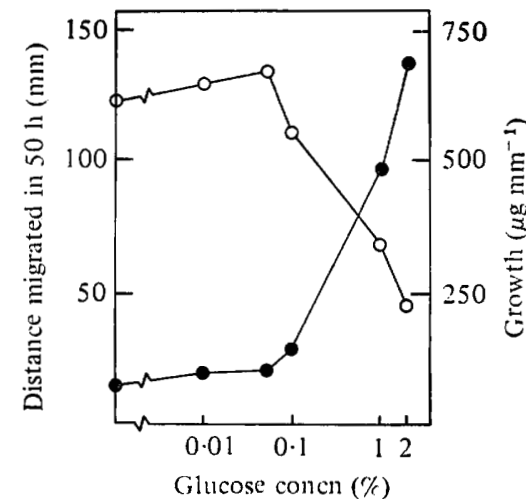

Fig. 3

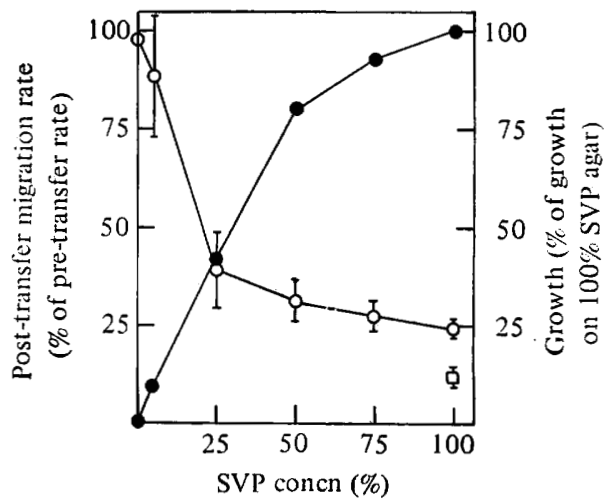

Fig. 4

Fig. 3. Effect of glucose on migration and growth on SVP agar. Mean distances migrated in $50 \mathrm{~h}$ (O) are each based on 12 replicates, and growth values (O) were determined as in Fig. 2 from 20 plasmodia harvested at intervals throughout the experiment.

Fig. 4. Effect of salts, vitamins and peptone (SVP) at various concentrations from standard SVP agar $(100 \%)$ to water agar $(0 \%)$ on migration $(\bigcirc)$ and growth $(\odot)$. The concentration of agar, the sole carbohydrate source, was $2 \%$. Plasmodia migrating on water agar were transferred to the experimental media and the migration rate from 1 to $6 \mathrm{~h}$ after transfer was measured and expressed as a percentage of the migration rate in the $4 \mathrm{~h}$ before transfer; each point is based on five replicates, vertical bars indicate standard errors. The migration rate on SVP $1 \%$ glucose agar is also included $(\square)$. The mean dry weights of sets of plasmodia that had migrated 200 to $300 \mathrm{~mm}$ were recorded, and the mean dry weights of a control set harvested at the time of transfer were deducted. The growth value, obtained by dividing the mean corrected dry weight by the post-transfer migration distance, is expressed as a percentage of that on standard SVP agar.

\section{Relationship between migration and growth at various nutrient concentrations}

Tracks of SVP agar containing glucose at various concentrations were inoculated with SVP $1 \%$ starch agar plugs bearing plasmodia. Growth was estimated by regression analysis as in Fig. 2 and migration was assessed by comparing the distances moved after $50 \mathrm{~h}$. Glucose at concentrations greater than $0.05 \%$ caused major increases in growth and reduction in migration rate (Fig. 3).

Although the migration rate on SVP agar was high compared with that on SVP 1\% glucose agar, it was low compared with that on water agar. Examination of the effect on migration and growth of SVP added at various concentrations to water agar (Fig. 4) indicated that the addition of other nutrients as well as carbohydrates resulted in an increase in growth and a depression of migration.

\section{Effect of sugars other than glucose on growth and migration}

The ability of a variety of sugars and derivatives when added at $56 \mathrm{~mm}$ to SVP agar to support growth and influence migration was examined (Table 1). The effectiveness of mannitol in supporting growth was unexpected, since at high concentration it induced sclerotium formation (Chet \& Rusch, 1969) and was assumed to be non-metabolizable by myxomycetes; experiments with liquid cultures, however, confirmed that it could support growth (Table 2). The ability of fructose to enhance growth on agar media was also unexpected, since Carlile (1970) found that fructose did not support growth when added to liquid media. However, further experiments with liquid cultures established that fructose was utilized and enhanced growth if glucose was present but was not utilized when it was the sole carbohydrate (Table 3); although only a small proportion of the fructose was utilized, yields in $\mathrm{mg}$ dry weight per $\mathrm{mg}$ carbohydrate consumed were similar for glucose $(1 \cdot 1)$ and fructose $(1 \cdot 2)$. This finding resolves controversy (Carlile, 1970) as to whether 


\section{Table 1. Effect of sugars at $56 \mathrm{mM}$ on growth and migration on SVP agar}

Plasmodia on SVP $1 \%$ starch agar plugs were placed at the end of agar tracks and subsequent growth and migration were recorded. Data were combined from several experiments, in each of which controls on SVP agar were included. The mean migration distance of the controls after $50 \mathrm{~h}$ was $118 \pm 3 \mathrm{~mm}$ and the growth was $71 \pm 4 \mu \mathrm{g} \mathrm{mm}^{-1}$ (standard errors indicated).

\begin{tabular}{lcc}
\multicolumn{1}{c}{ Compound* } & $\begin{array}{c}\text { Increased } \\
\text { growth } \dagger \\
\left(\mu \mathrm{g} \mathrm{mm}^{-1}\right)\end{array}$ & $\begin{array}{c}\text { Migration } \\
\text { inhibition } \\
(\%)\end{array}$ \\
Maltose & $581(0 \cdot 1)$ & $66(0 \cdot 1)$ \\
D-Glucose & $412(0 \cdot 1)$ & $45(0 \cdot 1)$ \\
D-Mannose & $160(0 \cdot 1)$ & $53(0 \cdot 1)$ \\
Mannitol & $132(0 \cdot 1)$ & $20(0 \cdot 1)$ \\
$N$-Acetyl-D-glucosamine & $54(0 \cdot 1)$ & $16(0 \cdot 5)$ \\
D-Fructose & $54(0 \cdot 1)$ & $13(0 \cdot 1)$ \\
D-Glucosamine.HCl & $48(0 \cdot 1)$ & $40(0 \cdot 1)$ \\
D-Galactose & $33(0 \cdot 5)$ & $19(0 \cdot 1)$ \\
D-Ribose & $18(0 \cdot 5)$ & $6(\mathrm{NS})$ \\
L-Arabinose & $15(0 \cdot 5)$ & $-4(\mathrm{NS})$ \\
D-Arabinose & $9(1 \cdot 0)$ & $-2(\mathrm{NS})$ \\
L-Sorbose & $12(\mathrm{NS})$ & $17(0 \cdot 1)$ \\
Sucrose & $7(\mathrm{NS})$ & $19(0 \cdot 1)$ \\
Methyl- $\alpha-D-g l u c o s i d e$ & $1(\mathrm{NS})$ & $-16(\mathrm{NS})$
\end{tabular}

* Concentrations of contaminating glucose in the stock sugars, determined by the glucose oxidase method (Barton, 1966), were (\%): $N$-acetyl-D-glucosamine, 0.04; D-fructose, $0 \cdot 12$; D-ribose, 0.03 ; L-arabinose, $0 \cdot 18$; L-sorbose, $0 \cdot 01$; methyl- $\alpha$-D-glucoside, 0.55 .

$\dagger$ Mean growth values were calculated by regression analysis from data plotted as in Fig. 2 . The values in this column were obtained after subtracting the control values. The significance of the difference $(\%)$ from that obtained with SVP agar, indicated in parentheses, was obtained by a test in which the ratio of the difference between the experimental and control values to their pooled standard error was compared to a $t$ variable (Moore \& Edwards, 1965). Ns indicates not significant at $10 \%$ level.

\$ Migration inhibition is based on comparison of the distances migrated in $50 \mathrm{~h}$ by experimental and control plasmodia. The significance of the difference $(\%)$, obtained by the $t$ test, is indicated in parentheses. NS indicates not significant at $10 \%$ level.

\section{Table 2. Growth of microplasmodia on mannitol}

Erlenmeyer flasks $(500 \mathrm{ml})$ containing $50 \mathrm{ml}$ media each received a $2.5 \mathrm{ml}$ inoculum from cultures at maximum growth on SVP $1 \%$ glucose, and were shaken at $200 \mathrm{rev} . \mathrm{min}^{-1}$, radius of gyration $45 \mathrm{~mm}$. The basal medium was SVP liquid, and the experimental flasks contained in addition $56 \mathrm{~mm}$ mannitol or glucose. After $4 \mathrm{~d}$ incubation, microplasmodia were harvested by centrifuging $(2500 \mathrm{~g}$, $5 \mathrm{~min}$ ), dried at $110^{\circ} \mathrm{C}$ for $15 \mathrm{~h}$ and weighed.

\begin{tabular}{lc}
\multicolumn{1}{c}{ Medium } & $\begin{array}{c}\text { Dry weight* } \\
\text { (mg) }\end{array}$ \\
SVP & $20 \pm 2$ \\
SVP mannitol & $228 \pm 13$ \\
SVP glucose & $427 \pm 17$
\end{tabular}

* Results show the mean of three replicates for each treatment, and the standard error. The dry weight of the inoculum was $21 \pm 1 \mathrm{mg}$.

fructose will support growth in myxomycetes, and explains fructose-enhanced growth on agar media, where agarose will be substituting for glucose. Growth did not occur in shaken liquid cultures of SVP medium supplemented with $56 \mathrm{~mm}$-methyl- $\alpha$-D-glucoside or with $56 \mathrm{~mm}$-2-deoxy-D-glucose; estimations of these compounds by gas-liquid chromatography of their silyl derivatives (Sweeley et al., 1963) showed that they had not been utilized.

\section{DISCUSSION}

Daniel (1964) stated that media able to support rapid growth depress migration; this has been confirmed. The mechanism by which growth promotion wholly or partially 
Table 3. Growth and fructose utilization in liquid SVP medium supplemented with glucose, fructose and both sugars

$\begin{array}{lcc}\begin{array}{c}\text { Carbohydrate* } \\ \text { (each at } 0 \cdot 2 \% \text { ) }\end{array} & \begin{array}{c}\text { Dry weight of } \\ \text { plasmodia } \dagger \text { (mg) }\end{array} & \begin{array}{c}\text { Residual } \\ \text { fructose } \dagger(\mathrm{mg})\end{array} \\ \text { Fructose } & & \\ \text { Day 0 } & 6 \pm 1 & 107 \pm 3 \\ \text { Day 4 } & 8 \pm 2 & 103 \pm 4 \\ \text { Glucose } & & - \\ \text { Day 0 } & 6 \pm 1 & - \\ \text { Day 4 } & 111 \pm 5 & \\ \text { Fructose+ Glucose } & & 109 \pm 3 \\ \text { Day 0 } & 6 \pm 1 & 91 \pm 2 \\ \text { Day 4 } & 133 \pm 7 & \end{array}$

\footnotetext{
* Carbohydrate solutions were filter-sterilized before being added to autoclaved SVP medium. This procedure resulted in sugar concentrations a little higher than $0.2 \%$. Assays of the uninoculated fructose and fructose plus glucose controls, at day 0 and day 4 , did not differ significantly and indicated $107 \pm 3 \mathrm{mg}$ fructose in $50 \mathrm{ml}$ medium, i.e. $0 \cdot 214 \%$.

$\dagger$ Results show the yield per flask $(50 \mathrm{ml}$ medium) and the standard error.

4 Fructose was assayed by the resorcinol method (Bacon \& Bell, 1948).
}

suppresses migration is unknown, but the response is clearly an appropriate one, causing the organism to remain at a site until nutrients are exhausted.

Depression of migration rate can also be brought about on SVP agar by some sugars, such as sucrose and sorbose at $56 \mathrm{~mm}$, which support little or no growth. This is probably due to the osmotic effects of the sugars, as was concluded by Denbo \& Miller (1976) for sucrose solutions with concentrations greater than 100 m-osmol. Leyrand et al. (1972) demonstrated osmotic effects on plasmodia with sucrose solutions as low as $25 \mathrm{~m}$-osmol, and considered how osmotic pressure could influence locomotion. We have shown that various compounds at $56 \mathrm{~mm}$, all of which produce similar external osmotic pressures, differ in the extent to which they depress migration, with some, such as methyl- $\alpha$-D-glucoside, having no significant effect at this concentration. Leyrand et al. (1972) found, however, that with sucrose concentrations of up to $100 \mathrm{~m}$-osmol complete adaptation occurred within $1 \mathrm{~h}$, such recovery presumably being due in part to penetration of the sucrose into the plasmodium. The different effects of the sugars tested in the present study could hence be due to different rates of permeation by the sugar, those penetrating less rapidly having a greater influence on migration.

We conclude, therefore, that sugars can depress migration in two ways; through an osmotic effect, and, if they are metabolizable and promote growth, through some unknown mechanism.

We wish to thank the Science Research Council for a studentship to one of us (D. J.C.K.), Dr A. G. Dickerson for his advice on carbohydrate assays, and Dr A. L. Cohen for access to unpublished information.

\section{REFERENCES}

Araki, C. J. (1966). Some recent studies on the polysaccharides of agarophytes. In Proceedings of the 5th International Seaweed Symposium, pp. 3-17. Edited by E. G. Young \& J. L. McLachlan. London: Plenum Press.

Bacon, J. S. D. \& Bell, D. J. (1948). Fructose and glucose in the blood of foetal sheep. Biochemical Journal 42, 397-405.

BARTON, R. R. (1966). A specific method of quan- titative determination of glucose. Analytical Biochemistry 14, 258-260.

Carlile, M. J. (1970). Nutrition and chemotaxis in the myxomycete Physarum polycephalum: the effect of carbohydrates on the plasmodium. Journal of General Microbiology 63, 221-226.

Carlile, M. J. (1971). Myxomycetes and other slime moulds. Methods in Microbiology 4, 237 265 . 
Carlile, M. J. (1972). The lethal reaction following plasmodial fusion between two strains of the myxomycete Physarum polycephalum. Journal of General Microbiology 71, 581-590.

Chet, I. \& Rusch, H. P. (1969). Induction of spherule formation in Physarum polycephalum. Journal of Bacteriology 100, 673-678.

Daniel, J. W. (1964). The nutritional requirements of a myxomycete as a function of its development cycle in pure culture. Tenth International Botanical Congress, Edinburgh, Abstracts of Papers, pp. 65-66.

Denbo, J. R. \& Miller, D. M. (1976). Factors affecting the movement of slime mould plasmodia. Comparative Biochemistry and Physiology 55A, 5-12.

Dodd, P. R., Pritchard, M. J., Adams, R. C. F., Bradford, H. F., Hicks, G. \& Blanshard, K. C. (1974). A method for the continuous, long term superfusion of the cerebral cortex of unanaesthetised, unrestrained rats. Journal of Physics E: Scientific Instruments 7, 897-901.

Leyrand, D. B., Matveeva, N. B., Teplov, V. A. \& Beylina, S. I. (1972). The role of elastoosmotic parameters in locomotion of myxomycete plasmodia. Acta protozoologica 11, 339-354.
Miller, D. M. \& Anderson, J. D. (1966). The morphology, migration and pressure development of oriented plasmodia of the slime mould. Transactions of the Illinois State Academy of Science 59, 352-357.

Miller, D. M. \& Anderson, J. D. (1971). Migration and biopotentials in slime mould plasmodia. Experiments in Physiology and Biochemistry 4, 183-202.

Moore, P. G. \& Edwards, D. E. (1965). Standard Statistical Calculations. London: Pitman.

Rose, L. E., Miller, D. M. \& Anderson, J. D. (1971). Gluccse inhibition of plasmodial migration in the acellular slime mould, Physarum polycephalum. Transactions of the Illinois State Academy of Science 65, 42-50.

SMITH, W. K. (1951). Improvements in the ionexchange method of preparing silica sols. Proceedings of the Society for Applied Bacteriology 14, 139-146.

SNedecor, G. W. \& Cochran, W. G. (1974). Statistical Methods, 6th edn. Ames, Iowa: Iowa State University Press.

Sweeley, C. C., Bentley, R., Makita, M. \& Wells, W. W. (1963). Gas liquid chromatography of trimethylsilyl derivatives of sugars and related substances. Journal of the American Chemical Society 85, 2497-2507. 